Original Article

\title{
DEVELOPMENT OF SPECTROPHOTOMETRIC AND FLUOROMETRIC METHODS FOR ESTIMATION OF DARUNAVIR USING QBD APPROACH
}

\author{
R. D. GODAMBE, J. I. DISOUZA, C. M. JAMKHANDI*, P. S. KUMBHAR \\ Tatyasaheb Kore College of Pharmacy Warananagar, Dist: Kolhapur (MS) India \\ Email: cmjamakhandi@gmail.com
}

Received: 22 Oct 2017, Revised and Accepted: 12 Dec 2017

\section{ABSTRACT}

Objective: The main objective of the present study is to develop newer simple, precise spectrophotometric and fluorometric methods of estimation for Darunavir using coupling agent $O$-pthaladehyde.

Methods: The experimental work was designed for both spectroscopic and fluorometric method development and validation. The method is based on formation complex of Darunavir with $O$-pthaladehyde. QbD approach was applied by varying different parameters. These parameters were designed into Ishikawa diagram.

Results: The complex Darunavir-Phthalaldehyde in methanol with $0.1 \mathrm{~N} \mathrm{HCl}$ showed linearity for both spectrophotometric and fluorometric methods. The calibration curve by spectrophotometry is linear in concentration range of $2-22 \mu \mathrm{g} / \mathrm{ml}$ with regression coefficient $\left(\mathrm{R}^{2}\right)=0.998$ at 355 $\mathrm{nm}$ and for fluorometry it is linear in concentration range of $0.5-5.0 \mathrm{ng} / \mathrm{ml}$ with regression coefficient (R2) $=0.999$. This method was found to be rugged and robust in different testing criteria with $\%$ RSD less than 2 . The limit of detection and limit of quantification was found to be $0.2 \mu \mathrm{g} / \mathrm{ml}$ and $0.8 \mu \mathrm{g} / \mathrm{ml}$ for a spectrophotometric method and $0.12 \mu \mathrm{g} / \mathrm{ml}$ and $0.43 \mu \mathrm{g} / \mathrm{ml}$ for fluorometric method respectively.

Conclusion: Both methods were found to be precise with \% RSD of less than 2. The \% recovery of the spectrophotometric and fluorometric methods was found to be $101.04 \%, 98.15 \%$ respectively. In this way, the results of all validation parameter were within the limits as per International Conference on Harmonization guideline.

Keywords: Spectrophotometry, Fluorometry, Darunavir, Condensation reaction

(C) 2018 The Authors. Published by Innovare Academic Sciences Pvt Ltd. This is an open access article under the CC BY license (http://creativecommons.org/licenses/by/4.0/) DOI: http://dx.doi.org/10.22159/ijcpr.2018v10i1.24401

\section{INTRODUCTION}

Darunavir (DRV) is an anti-retroviral drug and is inhibitor of the human immunodeficiency virus (HIV) protease in adults and children of age $6 \mathrm{y}$ and older [1]. It is a second-generation protease inhibitor, which is discovered to overcome the problems with early protease inhibitor (PIs) like severe side effects and drug toxicities, require a high therapeutic dose, are costly to manufacture, and show a disturbing susceptibility to drug-resistant mutations. DRV is used with ritonavir and other medications to treat HIV [2]. It works by slowing the spread of HIV in the body. Chemically it is [(1S, 2R)-3-[(4aminophenyl) sulfonyl] (2-methylpropyl) amino]-2-hydroxy-1(phenylmethyl) propyl]-carbamic acid $(3 R, 3 \mathrm{a} S, 6 \mathrm{a} R)$ hexahydrofuro [2, 3-b] furan-3-yl ester monoethanolate [3, 4] (fig. 1).

The Quality by Design (QbD) principles have been used to advance product and process quality, particularly in automotive industry, is systematic, risk-based approach in pharmaceutical product and analytical method development [5-7].

The three ICH guidelines which throw light upon quality-by-design and related aspects include Q8 Pharmaceutical development, Q9 Pharmaceutical risk management and Q10 Pharmaceutical Quality systems. In fact, the ICH guideline 08 is sub-divided into two parts: part one deal with pharmaceutical development and Part II is the annex to the guideline which states the principles for Quality-byDesign (QbD) [8-10].

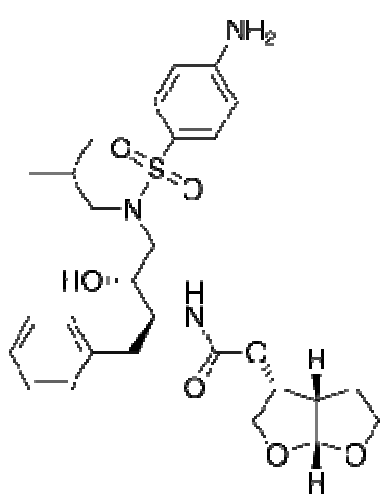

Fig. 1: Structure of darunavir ethanolate

There are various analytical methods developed for Darunavir [11] and drugs which can be made measurable by converting the drug into the complex by coupling reaction [12-14]. In the present study we have developed simple, precise, accurate, two analytical methods to determine the Darunavir, coupling it with $o$-Phthalaldehyde in methanolic media by a condensation reaction (fig. 2).

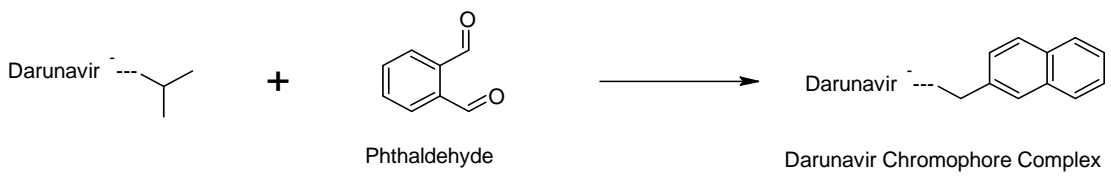

Chromophore

Fig. 2: Formation of darunavir- $O$-phthalaldehyde complex 
Table 1: List of materials used for research work

\begin{tabular}{ll}
\hline Materials & Source \\
\hline Darunavir & Cipla Pvt. Ltd \\
O-Phthalaldehyde & Sigma Aldrich \\
$0.1 \mathrm{~N}$ Sodium Hydroxide & Laysan Bio Inc. \\
0.1 N Hydrochloric acid & Fine Chemical Industries, Mumbai \\
Methanol & Fine Chemical, Mumbai \\
Distilled water & - \\
\hline
\end{tabular}

Table 2: List of instruments/Equipments used for research

\begin{tabular}{ll}
\hline Instruments/Equipments & Source \\
\hline Electronic Balance & Shimadzu AUW 220D \\
Magnetic Stirrer & Remi Equipment Pvt. Ltd. \\
Centrifuge & Remi Equipment Pvt. Ltd. \\
UV-Visible Spectrophotometer & Agilent Technology Carry 60 UV-vis UV-1800 Shimadzu, Japan \\
Micropipettes & Swastik Instrument Private Ltd. Mumbai \\
Ultrasonicator & Quality Equipment and Instrument \\
Mechanical Shaker & Remi Equipment Pvt. Ltd \\
Fluorometer & Systronics \\
\hline
\end{tabular}

\section{MATERIALS AND METHODS}

The material mentioned (table 1 ) in the procedure are all pure and analytical grade and equipment and machinery used in the procedure are prior to use are calibrated (table 2).

\section{Method development by QbD approach}

Method development using Quality by Design approach can be divided into following steps:

- Definition of method goals

- Risk assessment

- Design of experiment with optimization

- MODR (Method Operable Design Region), working point selection and verification

- Method Control Strategy based on the knowledge gained about the developed method [15-20].

\section{Definition of method goals}

The primary aim was to develop a more robust method and validation of the developed method. Quality by Design approach was applied to get MODR (Method Operable Design Region). MODR is defined as the set of method parameters over which the robustness and ruggedness experimentation has shown the method can meet the requirements of the ATP [21-23].

\section{Risk assessment}

In this stage of $\mathrm{QbD}$ approaches critical parameters that affect the overall quality of method were identified such as $\mathrm{pH}$, wavelength, scan speed, temperature and stirring time of complex prepared.

\section{Design of experiment}

In the design of the experiment, factors like nature of the solvent, $\mathrm{pH}$ of the complex and stirring time were considered.

\section{Preparation of complex of darunavir with coupling reagent}

The complex of Darunavir with $O$-Phthalaldehyde was prepared in methanol by three different strategies

a. The complex of Darunavir was prepared by a coupling reaction with $O$-Phthalaldehyde in methanol.

b. The complex of Darunavir was prepared by a coupling reaction with $O$-Phthalaldehyde in methanol using $0.1 \mathrm{~N}$ sodium hydroxide.

c. The complex of Darunavir was prepared by a coupling reaction with $O$-Phthalaldehyde in methanol using $0.1 \mathrm{~N}$ Hydrochloric acid.

\section{Preparation of standard stock solutions}

Accurately weighed $10 \mathrm{mg}$ Darunavir was dissolved in $10 \mathrm{ml}$ methanol in a volumetric flask $(1000 \mu \mathrm{g} / \mathrm{ml}) .1 \mathrm{ml}$ sample from $(1000 \mu \mathrm{g} / \mathrm{ml})$ solution was diluted up to $10 \mathrm{ml}$ with methanol so as to get the solution of concentration $(100 \mu \mathrm{g} / \mathrm{ml})$. Then $1 \mathrm{ml}$ sample from $(100 \mu \mathrm{g} / \mathrm{ml})$ solution was diluted up to $10 \mathrm{ml}$ with methanol so as to get the solution of concentration $(10 \mu \mathrm{g} / \mathrm{ml})$. This solution was treated as stock solutions and three sets of dilutions were prepared by using these stock solutions.

Preparation of working solutions and determination of $\lambda$ max

Three different types of working solutions of varying concentration were prepared by using standard stock solutions, $0.1 \% \mathrm{w} / \mathrm{v} O$ Phthalaldehyde solution in methanol, $0.1 \mathrm{~N} \mathrm{NaOH}$ solutions and 0.1 $\mathrm{N} \mathrm{HCl}$ solutions.

Preparation of working solution by using standard stock solutions and $0.1 \% \mathrm{w} / \mathrm{v} O$-Phthalaldehyde solution

$0.2,0.4,0.6,0.8,1.0,1.2,1.4,1.6,1.8,2.0$ and $2.2 \mathrm{ml}$ of solutions were removed from standard stock solution of concentration $100 \mu \mathrm{g} / \mathrm{ml}$ to these $1.0 \mathrm{ml}$ of $0.1 \% \mathrm{w} / \mathrm{v} O$-Phthalaldehyde solution was added and final volume was adjusted up to $10 \mathrm{ml}$ with methanol so as to obtain final concentrations of $2,4,6 \mu \mathrm{g} / \mathrm{ml}$ etc.

Spectrophotometric method: The $\lambda$ max was determined by scanning one of the solutions over the range of $200-800 \mathrm{~nm}$ by using UV-Visible spectrophotometry and $\lambda$ max was found to be $249 \mathrm{~nm}$ in methanol.

Flourometric method: The dilute solutions of conc.0.5-5.0 ng/ml were prepared and analysed by fluorometry.

Preparation of working solution by using standard stock solutions, $0.1 \% \mathrm{w} / \mathrm{v} O$-Phthalaldehyde solution and $0.1 \mathrm{~N}$ Hydrochloric acid

$0.2,0.4,0.6,0.8,1.0,1.2,1.4,1.6,1.8,2.0$ and $2.2 \mathrm{ml}$ of solutions were removed from standard stock solution of concentration $100 \mu \mathrm{g} / \mathrm{ml}$ to these $1.0 \mathrm{ml}$ of $0.1 \% \mathrm{w} / \mathrm{v}$ 0-Phthalaldehyde solution and $1 \mathrm{ml} 0.1 \mathrm{~N}$ Hydrochloric acid were added to each and final volume was adjusted upto $10 \mathrm{ml}$ with methanol so as to obtain final concentrations of 2.0,4.0, $6.0 \mu \mathrm{g} / \mathrm{ml}$ etc. Spectrophotometric method: The $\lambda$ max was determined by scanning one of the solutions over the range of $200-800 \mathrm{~nm}$ by using UV-Visible spectrophotometry and $\lambda$ max was found to be $355 \mathrm{~nm}$ in $0.1 \mathrm{~N}$ Hydrochloric acid.

Flourometric method: The dilute solutions of conc.0.5-5.0 ng/ml were prepared and analysed by fluorometry.

Preparation of working solution by using standard stock solutions, $0.1 \% \mathrm{w} / \mathrm{v} O$-Phthalaldehyde solution and $0.1 \mathrm{~N}$ Sodium hydroxide

$0.2,0.4,0.6,0.8,1.0,1.2,1.4,1.6,1.8,2.0$ and $2.2 \mathrm{ml}$ of solutions were removed from standard stock solution of concentration $100 \mu \mathrm{g} / \mathrm{ml}$ 
to these $1.0 \mathrm{ml}$ of $0.1 \% \mathrm{w} / \mathrm{v} 0$-Phthalaldehyde solution and $1 \mathrm{ml} 0.1$ $\mathrm{N}$ sodium hydroxide solution were added to each and final volume was adjusted upto $10 \mathrm{ml}$ with methanol so as to obtain final concentrations of $2.0,4.0,6.0 \mu \mathrm{g} / \mathrm{ml}$ etc.

Spectrophotometric method: The $\lambda_{\max }$ was determined by scanning one of the solutions over the range of $200-800 \mathrm{~nm}$ by using UVVisible spectrophotometry and $\lambda_{\max }$ was found to be $367 \mathrm{~nm}$ in $0.1 \mathrm{~N}$ Sodium hydroxide.

Flourometric method: The dilute solutions of conc.0.5-5.0 ng/ml were prepared and analysed by fluorometry.

\section{Construction of calibration curve}

The absorbance of dilutions prepared above was measured at respective $\lambda$ max found for each complex against methanol as a blank and recorded. The calibration curve was plotted using absorbance $\mathrm{v} / \mathrm{s}$ concentration. Then the linear equation and regression coefficient were calculated.

\section{Validation of the analytical method developed}

After development and optimization of the method, the following parameters were evaluated: Selectivity, robustness, linearity, limit of detection, limit of quantification, precision and accuracy. These parameters were evaluated according to the standards set by ICH. A risk-based approach based on the QbD principles set out in ICH Q8 and Q9 was applied to the evaluation of method robustness and ruggedness. Structured methodologies for risk assessment, such as Fishbone diagram can be implemented to identify the potential risk of the method due to a small change in method parameters or under a variety of conditions such as different laboratories, analysts, instruments, reagents, days, etc.

\section{Linearity and range}

The linearity of an analytical method is its ability to produce test results that are directly proportional to the concentration of an analyte in the sample within a given range. Linearity and range of optimized method were determined by taking absorbance of dilutions prepared of DRV-PTH complex in methanol with $0.1 \mathrm{~N} \mathrm{HCl}$ at $355 \mathrm{~nm}$ using methanol as a blank and plotting the graph of absorbance $\mathrm{v} / \mathrm{s}$ concentration. Finally, the linear equation and regression coefficient was calculated and the range was decided.

\section{Accuracy and recovery study}

This study was carried out using the 20 tablets (Prezista). 20 tablets were weighed and powdered. The powder sample equivalent to 300 $\mathrm{mg}$ of active ingredients was weighed and dissolved in $300 \mathrm{ml}$ of methanol $(1000 \mu \mathrm{g} / \mathrm{ml})$ and allowed to sonicate for $10 \mathrm{~min}$. The study was performed at three levels by preparing sample solution concentration of $2.0 \mu \mathrm{g} / \mathrm{ml}, 4.0 \mu \mathrm{g} / \mathrm{ml}$ and $6.0 \mu \mathrm{g} / \mathrm{ml}$ using a solution of concentration $10 \mu \mathrm{g} / \mathrm{ml}$. The readings (absorbance) of these concentrations were recorded. Then the \% RSD of the concentrations was calculated.

The accuracy of the proposed methods was assessed by recovery studies at three different levels. Recovery studies were carried out by standard addition method. It was performed by adding a known amount of DRV solution of the drug to pre-analyzed tablet solutions. The resulting solutions were then reanalyzed by proposed methods.

\section{Precision}

The precision is a measure of the degree of reproducibility or repeatability of an analytical method. It provides an indication of random error. The precision of an analytical method is usually expressed as the standard deviation, relative standard deviation or coefficient of variance of a series of measurements. The two types of precision study intra-day and inter-day were performed by analyzing the diluted working solutions for three times within a day (intra-day) and analyzing the same solutions for three different days (interday) precision study.

\section{LOD and LOQ}

The limit of quantification (LOQ) is the lowest amount of analyte in a sample that can be determined with acceptable precision and accuracy. The LOD and LOQ were determined by using following formulae.

$$
L O D=\frac{3.3 \sigma}{S} \operatorname{LOQ}=\frac{10 \sigma}{S}
$$

$\sigma=$ Standard deviation

$\mathrm{S}=$ slope of the calibration curve

\section{Ruggedness}

The ruggedness of analytical method is the degree of reproducibility of test results obtained by the analysis of the same samples under a variety of conditions such as different laboratories, different instruments, different lots of reagents, different assay, temperatures, different days, different analysts, etc.

The ruggedness of analytical method was performed by analyzing the diluted working solutions by using Agilent and Shimadzu UVVisible spectrophotometer and by two different analysts.

\section{RESULTS AND DISCUSSION}

\section{Determination of $\lambda$ max}

The $\lambda_{\max }$ of complex solutions and plane DRV in methanol, Sodium hydroxide and Hydrochloric acid observed are reported (table 3) and represented (fig. 3 to 6).

Table 3: Wavelength of maximum absorbance $\left(\lambda_{\max }\right)$

\begin{tabular}{ll}
\hline Complex & $\boldsymbol{\lambda}$ max (nm) \\
\hline DRV in methanol & 255 \\
DRV-PTH complex in Methanol & 249 \\
DRV-PTH complex in Methanol with 0.1 N NaOH & 367 \\
DRV-PTH complex in Methanol with 0.1 N HCl & 355 \\
\hline
\end{tabular}

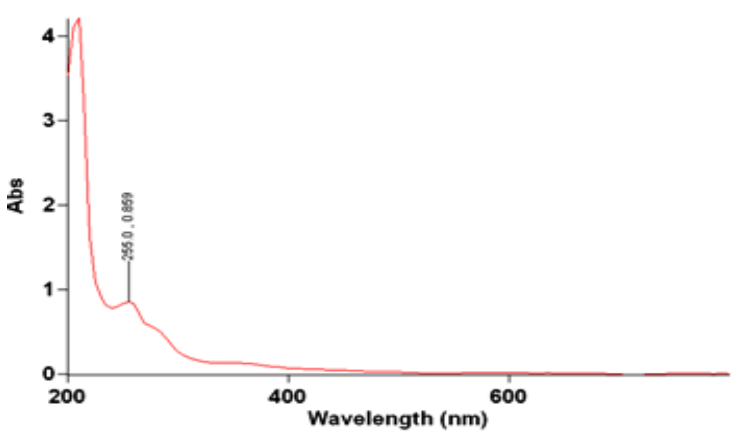

Fig. 3: UV-Visible absorption spectrum of DRV in methanol

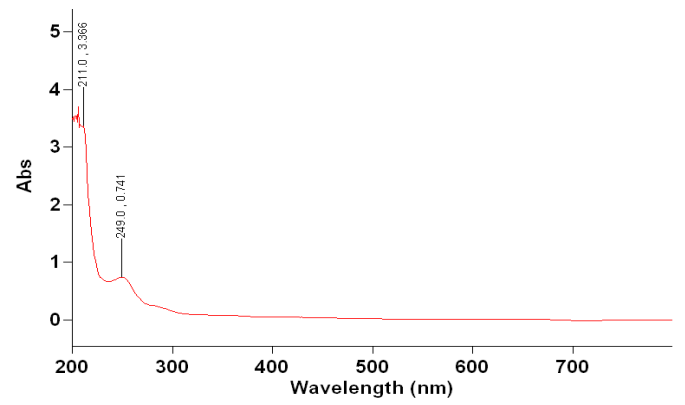

Fig. 4: UV-Visible absorption spectrum of DRV-PTH complex in methanol 


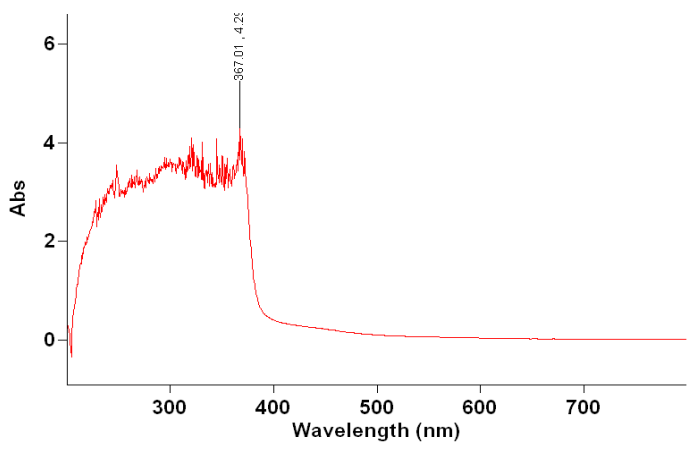

Fig. 5: UV-Visible absorption spectrum of DRV-PTH complex in methanol with $0.1 \mathrm{~N} \mathrm{NaOH}$

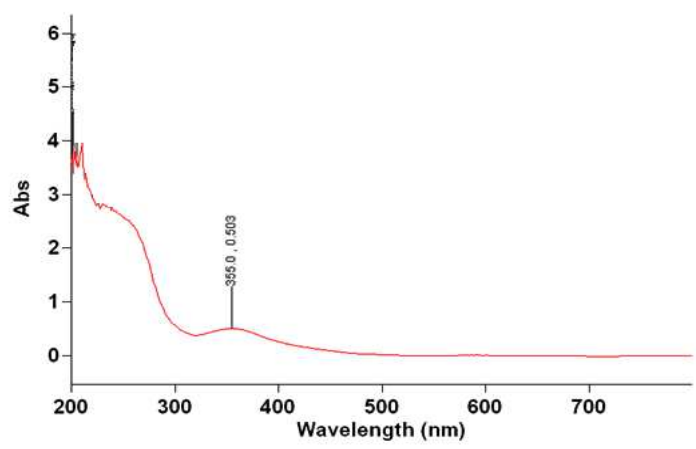

Fig. 6: UV-Visible absorption spectrum of DRV-PTH complex in methanol with $0.1 \mathrm{~N} \mathrm{HCl}$

\section{Linearity curve of complexes}

The graph of concentration vs. absorbance of three complexes was plotted. It was found that the graph of DRV-PTH complex in Methanol and DRV-PTH complex in Methanol with $0.1 \mathrm{~N} \mathrm{NaOH}$ was not linear while that of DRV-PTH complex in Methanol with $0.1 \mathrm{~N}$ $\mathrm{HCl}$ was linear in concentration range $2.0-22 \mu \mathrm{g} / \mathrm{ml}$ at $355 \mathrm{~nm}$. The DRV-PTH complex in Methanol with $0.1 \mathrm{~N} \mathrm{HCl}$ obeys Beer-Lamberts law in the range $4.0-22.0 \mu \mathrm{g} / \mathrm{ml}$ by spectrophotometric method. The linearity curve of DRV-PTH complex in methanol with $0.1 \mathrm{~N} \mathrm{HCl}$ using spectrophotometric method was shown (fig. 7). Fluorometric method for DRV-PTH complex in Methanol and DRV-PTH complex in Methanol with $0.1 \mathrm{~N} \mathrm{NaOH}$ was not linear while that of DRV-PTH complex in Methanol with $0.1 \mathrm{~N} \mathrm{HCl}$ was linear in concentration range $0.5-5.0 \mathrm{ng} / \mathrm{ml}$ at $355 \mathrm{~nm}$. The linearity curve of DRV-PTH complex in methanol with $0.1 \mathrm{~N} \mathrm{HCl}$ by fluorometric method was shown in (fig. 8).

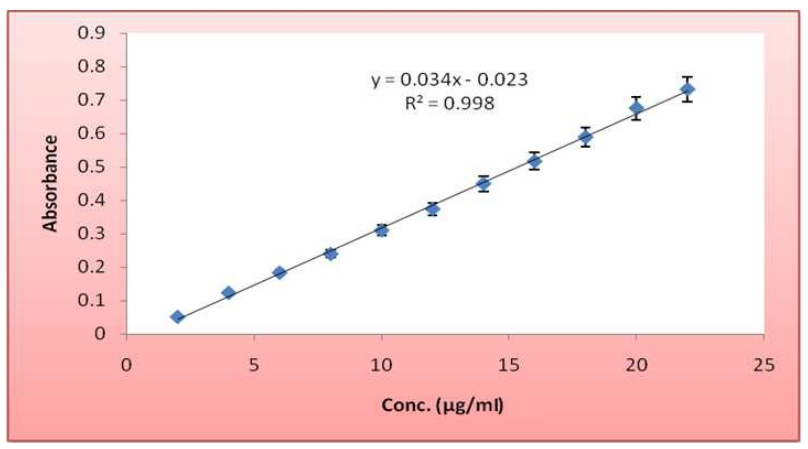

Fig. 7: Linearity curve of DRV-PTH complex in methanol with $0.1 \mathrm{~N} \mathrm{HCl}$ by agilent $\mathrm{UV}$-visible spectrophotometer

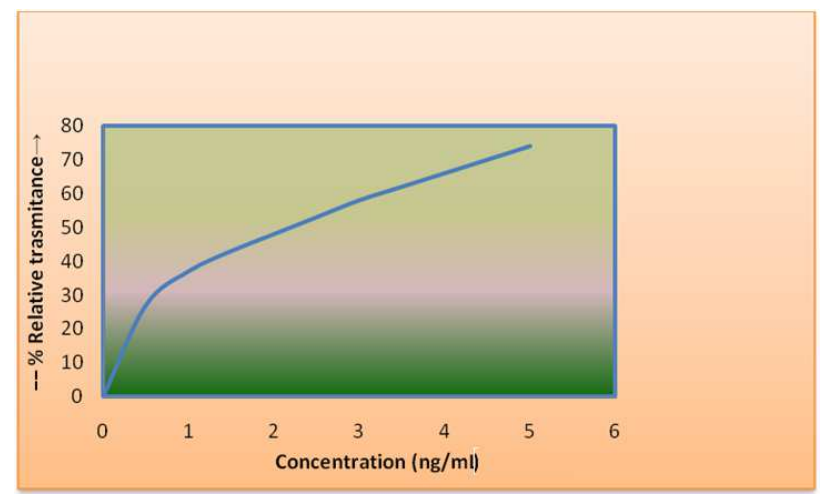

Fig. 8: Linearity curve of DRV-PTH complex in methanol with $0.1 \mathrm{~N} \mathrm{HCl}$ by a fluorometer

Table 4: Linearity and range parameters for spectrophotometric method

\begin{tabular}{ll}
\hline Statistical parameters & Values \\
\hline Correlation coefficient & 0.998 \\
Slope & 0.034 \\
Intercept & 0.023 \\
Range & $2-22 \mu \mathrm{g} / \mathrm{ml}$ \\
Standard deviation & 0.0035 \\
RSD & 0.0077 \\
\hline
\end{tabular}

Table 5: Linearity and range parameters for fluorometric method

\begin{tabular}{ll}
\hline Statistical parameters & Value \\
\hline Correlation & 0.997 \\
Slope & 17.72 \\
Intercept & 2.954 \\
Range & $0.5-5 \mathrm{ng} / \mathrm{ml}$ \\
SDV & 0.763 \\
RSD & 0.01 \\
\hline
\end{tabular}

The critical parameter extracted for both methods were studied (table 6 and 7). The Ishikawa fishbone diagram for spectrophotometric and fluorometric methods was also studied (fig. 9 and 10 ). 
Table 6: Critical attributes extracted for spectrophotometric method

\begin{tabular}{ll}
\hline Parameters & Extracted result \\
\hline $\mathrm{pH}$ & Acidic \\
Wavelength & $355 \mathrm{~nm}$ \\
Scan speed & Medium \\
Temperature & $0-8^{\circ} \mathrm{C}$ and $30-35^{\circ} \mathrm{C}$ \\
Stirring time & 5 and 10 min \\
\hline
\end{tabular}

Table 7: Critical attributes extracted for fluorometric method

\begin{tabular}{ll}
\hline Parameters & Extracted result \\
\hline $\mathrm{pH}$ & Acidic \\
Sensitivity & 0.2 and 2 \\
Temperature & $0-8{ }^{\circ} \mathrm{C}$ and $30-35^{\circ} \mathrm{C}$ \\
Stirring time & 5 and 10 min \\
\hline
\end{tabular}

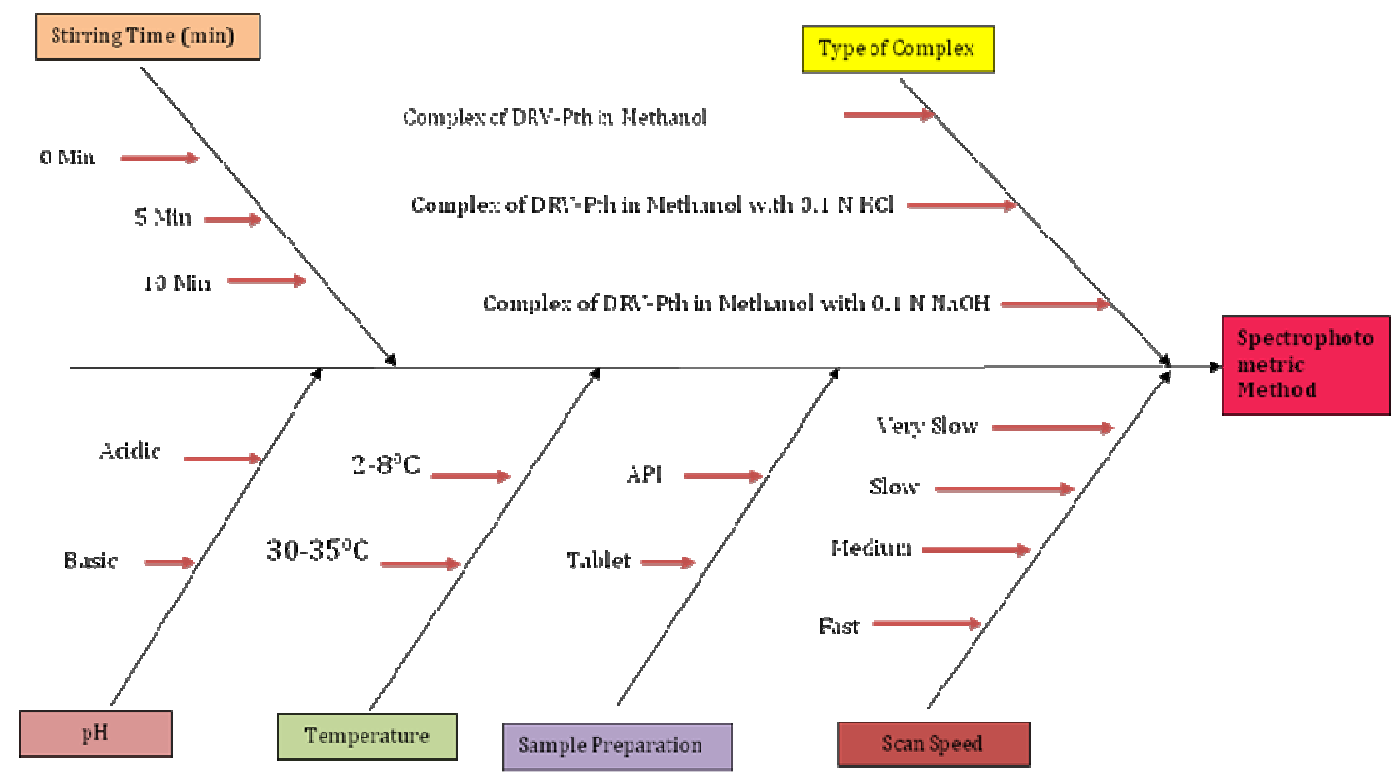

Fig. 9: Ishikawa diagram for a spectrophotometric method

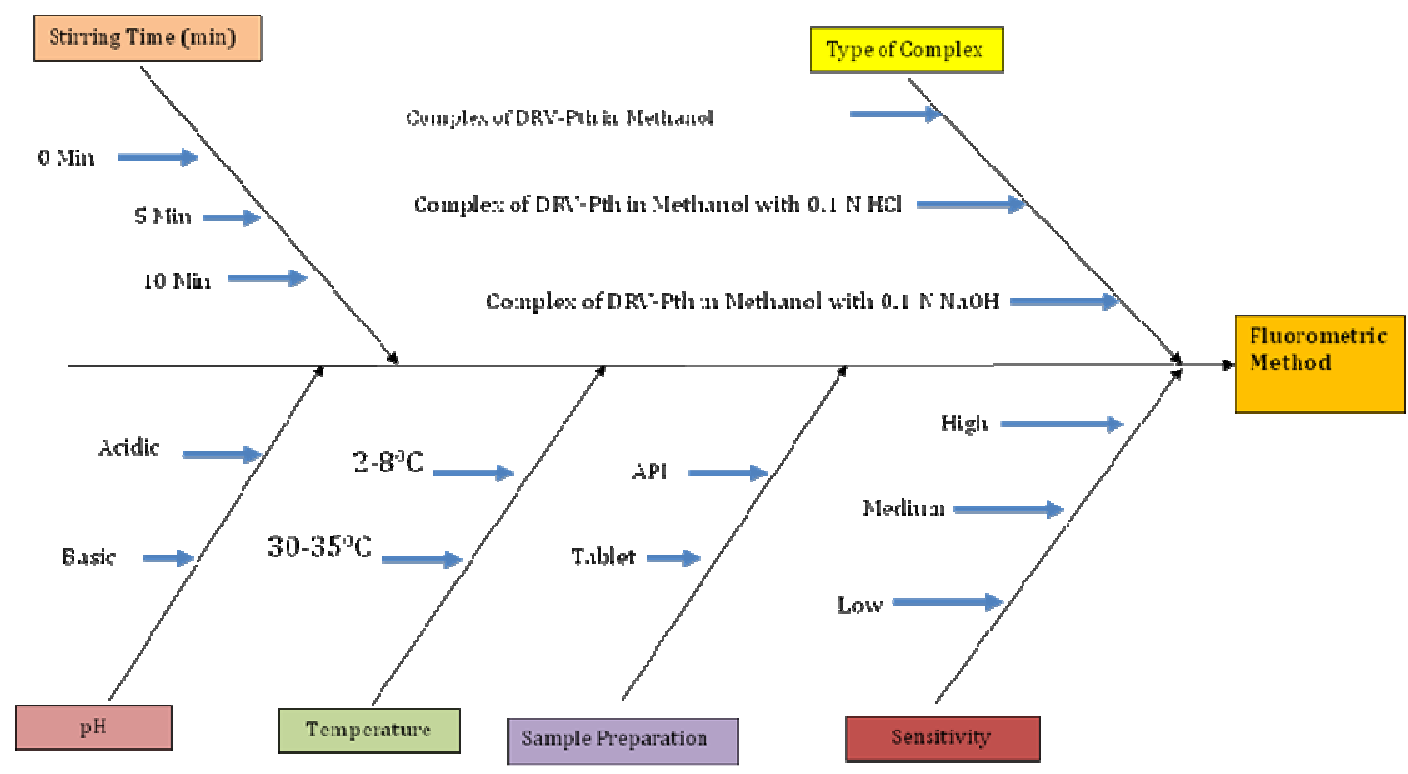

Fig. 10: Ishikawa diagram for a fluorometric method 


\section{Validation of analytical method}

The above-optimized method of DRV-PTH complex in methanol with $0.1 \mathrm{~N} \mathrm{HCl}$ was validated for a different parameter like precision, accuracy and recovery, LOD, LOQ, robustness and ruggedness for both analytical methods (table 8 and 9). The values of analytical parameters were found to be within standard limits.

\section{Precision (Repeatability)}

The spectrophotometric method for DRV-PTH complex in methanol with $0.1 \mathrm{~N} \mathrm{HCl}$ was found to be precise as indicated by intraday and interday analysis showing \% RSD less than 2 . The intraday and interday precision values observed were calculated. The fluorometric method for DRV-PTH complex in methanol with $0.1 \mathrm{~N}$ $\mathrm{HCl}$ was also found to be precise as indicated by intraday and interday analysis showing \% RSD less than 2 . The intraday and interday precision values observed by a fluorometric method.

\section{Accuracy and recovery}

The accuracy of the method was performed by calculating \% recovery of Darunavir by the standard addition method. The \% recovery of Darunavir by spectrophotometric method was found to be $101.04 \%$ and $98.15 \%$ by a fluorometric method. Accuracy data by spectrophotometric and fluorometric method (fig. 11).

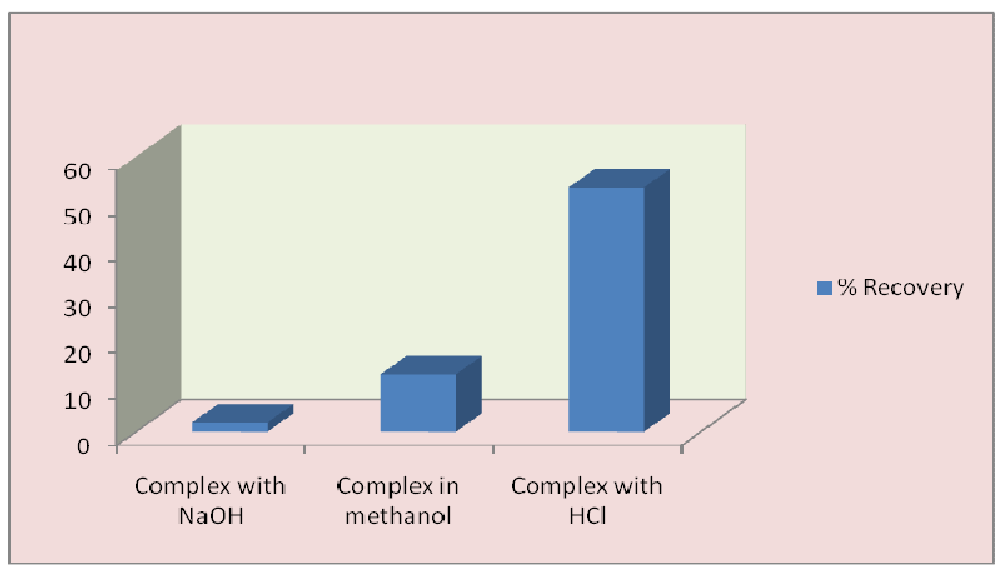

Fig. 11: Accuracy data by the spectrophotometric method

\section{Limit of detection}

The limit of detection by spectrophotometric and fluorometric method was found to be $0.2 \mu \mathrm{g}$ and $0.129 \mathrm{ng}$ respectively.

\section{Limit of quantification}

The limit of quantification by spectrophotometric and fluorometric method was found to be $0.8 \mu \mathrm{g}$ and $0.43 \mathrm{ng}$ respectively.

\section{Robustness}

The robustness of analytical method at various temperatures and stirring time was performed and the results of the same are presented for a spectrophotometric method and fluorometric method. There was no significant difference observed in \% RSD at 2$8{ }^{\circ} \mathrm{C}$ and $30-35{ }^{\circ} \mathrm{C}$ and different stirring time by the spectrophotometric and fluorometric method.

Table 8: Statistical data of validation by spectrophotometric method

\begin{tabular}{ll}
\hline Statistical parameter & Value \\
\hline$\lambda$ max & $355 \mathrm{~nm}$ \\
Correlation Coefficient & 0.998 \\
Slope & 0.034 \\
Intercept & 0.023 \\
Range & $2-22 \mu g / m l$ \\
SD & 0.0035 \\
RSD & 0.0077 \\
Precision (\% RSD) & 0.440 \\
Intraday & 0.459 \\
Interday & $101.04 \%$ \\
Recovery & 0.2 \\
LOD & 0.8 \\
LOQ & \\
\hline
\end{tabular}

Table 9: Statistical data of validation by fluorometric method

\begin{tabular}{ll}
\hline Statistical parameter & Value \\
\hline Correlation Coefficient & 0.997 \\
Slope & 17.72 \\
Intercept & 2.954 \\
Range & $0.5-5 \mathrm{ng} / \mathrm{ml}$ \\
SD & 0.763 \\
RSD & 0.01 \\
Precision (\% RSD) & 1.774 \\
Intraday & 0.201 \\
Interday & $98.15 \%$ \\
Recovery & 0.129 \\
LOD & 0.43 \\
LOQ & \\
\hline
\end{tabular}




\section{Ruggedness}

The ruggedness study was performed by two different analysts in the same laboratory. There was reproducibility in the result obtained by two different analysts.

\section{CONCLUSION}

Two simple, easily accessible and economic analytical methods like spectrophotometric and fluorometric methods were developed by QbD approach for Darunavir. The Darunavir was coupled with 0paraldehyde to form complex that was measured in the UV-Visible spectroscopic region $(\lambda \max 355 \mathrm{~nm})$. The same complex was fluorescent and analyzed by Fluorometry thus another analytical method was developed. While developing Spectrophotometric method quality was ensured by changing the experimental environments. Some of the experimental parameters changed to inculcate quality were the $\mathrm{pH}$ and physical parameters. The Darunavir and 0-Phthalaldehyde complex was first measured in methanol solvent. Then reaction media was made acidic with $\mathrm{HCl}$ and response was recorded. With $\mathrm{NaOH}$ making media basic the measurements were made and the response was recorded. The methods thus developed were validated for linearity, accuracy specificity, precision, percentage recovery, ruggedness and robustness. The validation parameters were calculated and expressed in statistical terms. It was found that all the values of the parameters were within the normal range. The developed methods were compared and it was concluded that the method in acidic media was more accurate, specific and precise. The interference of fluorescent property of complex was not considered for the UVVisible Spectroscopic method.

Similarly, the Fluorometric method was also developed with Darunavir complex which was sensitive; easily accessible was validated for linearity, accuracy specificity, precision, percentage recovery, ruggedness and robustness. On the calculation of validation parameters and statistical expression, all the parameters were showed the values within the normal range.

32 factorial design was employed wherein concentration, temperature and scan speed were selected as dependent variables. The factors were operated at 3 levels.

$(-1,0,+1)$ and linearity was selected as dependent factor.

Thus developed methods are simple, easily accessible, and economic. Does not require stringent expertise in performing and further are of immense useful in quality control and estimation of Darunavir.

\section{ACKNOWLEDGEMENT}

Authors are thankful to Hon'ble Dr. Vinayraoji V Kore President of Shree Warana Vibhag Shikshan Mandal Warananagar for continuous encouragement and support.

\section{AUTHORS CONTRIBUTIONS}

All the author have contributed equally

\section{CONFLICT OF INTERESTS}

Declared none

\section{REFERENCES}

1. Rodger D. MacArthur "Darunavir: promising initial results". Doi:10.1016/S0140-673660499-1.

2. Meyer S, Azijn H, Surleraux D, Jochmans D, Tahri A. TMC114, a novel human immunodeficiency virus type 1 protease inhibitor active against protease inhibitor-resistant viruses, including a broad range of clinical isolates. Antimicrob Agents Chemother 2005;49:2314-21.

3. Tie Y, Boross PI, Wang YF, Gaddis L, A Hussain K. Highresolution crystal structure of HIV-1 protease with a potent non-peptide inhibitor active against multi-drug resistant. J Mol Biol 2004;338:341-52.

4. King N, Jeyabalan M, Nalivaika E, PM Wigerinck, C Bethun. Schiffer, the structural and thermodynamic basis for the binding of TMC114, a next-generation human immunodeficiency virus type 1 protease inhibitor. J Virol 2004;78:12012-21.

5. Nishendu P, Nadpara, Rakshit V, Thumar, Vidhi N, Kalola, et al. International Journal of pharmaceutical sciences review and research. Rev Res 2012;17:20-8.

6. Ermer J. Quality by design in pharmaceutical analysis. Conference organized by European Compliance Academy, Vienna, Austria; 2013.

7. Warf SF. The state of QbD in the biopharmaceutical industry conference criticality assessment, design space implementation and control" in Proceedings of the Conference Sponsored by ISPE-Endorsed by CASSS with a Mutual Commitment to Quality Products, San Francisco, Calif, USA; 2013.

8. Lawrence XYu. Pharmaceutical quality by design: product and process development, understanding, and control. Pharma Res 2008;25:781-91.

9. Nethercote P, Borman P, Bennett T, Martin G, McGregor P. QbD for better method validation and transfer; 2010. Available from: http://www.pharmamanufacturing. com/articles/2010/ 060.html [Last accessed on 20 0ct 2017].

10. Elder P, Borman P. Improving analytical method reliability across the entire product lifecycle using QbD approaches. Pharm Outsourcing 2013;14:14-9.

11. Correa JC, D Arcy DM, Serra CH, Salgado HR. A critical review of properties of darunavir and analytical methods for its determination. Crit Rev Anal Chem 2014;44:16-22.

12. CM Jamakhandi, Chandrashekar Javali, Santosh Kumar, Sanjay Kumar DS, Dayanand Kadadevar. New fluorimetric method of development for lisinopril by a condensation reaction. Int J Pharm Pharm Sci 2010;2:209-11.

13. CM Jamakhandi, C Javali, JI Disouza, US Chougule, AK Mullani. Spectrophotometric determination of lisinopril dosage form by a condensation reaction. Int J Pharm Pharm Sci 2011;3:185-7.

14. International Conference on Harmonisation Tripartite Guideline Q9 Pharmaceutical Risk Management; 2005.

15. P Elliott, S Billingham, J Bi, Hu Zhang. Quality by design for biopharmaceuticals: a historical review and guide for implementation. Pharm Bioprocessing 2013;1:105-22.

16. $\mathrm{P}$ Borman. The application of quality by design to analytical methods. Pharma Tech 2007;31:142-52.

17. J Castillo, O Benavente, F Borrego, J Delri. Analysis of commercial hesperidin methyl chalcone by high-performance liquid chromatography. J Chromatography 1991;555:285-90.

18. Leposava M Jasmina. Development and validation of a fluorometric method for the determination of hesperidin in human plasma and pharmaceutical forms. J Serb Chem Soc 2012;77:1625-40.

19. International Conference on Harmonization (ICH) of Technical Requirements for Registration of Pharmaceuticals for Human Use, Topic Q9: Quality Risk Management, Geneva; 2005.

20. Y Li, GJ Terfloth, AS Kord. A systemic approach to RP-HPLC method development in a pharmaceutical QbD environment. Am-Pharma 2009;12:571-83.

21. FDA, Pharmaceutical GMPs for the 21st century-a risk-based approach (U. S Department of health and human services, Food and Drug Administration, U. S Government Printing Office, Washington DC; 2002.

22. MR Ghante, RS Shelar, SD Sawant, MM Kadam. Development and validation UV-spectrophotometric method for estimation of darunavir ethanolate in bulk and tablet dosage form. Int J Pharma Pharm Sci 2014;6:240-2.

23. K Balamuralikrishna. Development and validation of analytical procedure for the simultaneous estimation of efavirenz, lamivudine and zidovudine through new RP-HPLC method. J Pharm Res 2011;4:3766-8. 